\title{
INDÚSTRIA DA CONSTRUÇÃO CIVIL E BLOCO NO PODER (2011-2016)
}

\author{
CIVIL CONSTRUCTION INDUSTRY AND BLOCK ON POWER (2011-2016)
}

\author{
Octávio Fonseca Del Passo ${ }^{1}$
}

${ }^{1}$ Programa de Pós-Graduação em Ciência Política (PPGCP) da Universidade Estadual de Campinas (UNICAMP). E-mail: octaviodelpasso@gmail.com.

\author{
A R T I C LE INFO \\ Article history: \\ Received 2019-07-05 \\ Accepted 2019-09-06 \\ Available online 2019-09-06
}

Palavras-chave: Neodesenvolvimentismo. Dilma Rousseff. Construção Civil. Operação Lava Jato.

Keywords: Neodesenvolvimentism. Dilma Rousseff. Construction Industry. Operation Lava Jato.

RESUMO. A crise política e econômica no Brasil teve como fundamento a reorganização das classes no bloco no poder. Este artigo tem como objeto a indústria da construção civil no Brasil ao longo dos governos Dilma Rousseff (2011-2016). Utilizamos os conceitos de fração burguesa e de bloco no poder desenvolvidos por Nicos Poulantzas para explicar importantes conflitos presentes no processo político brasileiro. Nossa hipótese é que durante a crise do governo de Dilma Rousseff existiu um acirramento da disputa pelo orçamento público entre as frações burguesas, e isso induziu a uma alteração da posição política do médio capital da construção civil, que deixou de cumprir um papel subordinado ao grande capital e passou atuar abertamente contra ele. Em outras palavras, o médio capital da construção civil constituiu-se enquanto fração autônoma da classe capitalista, a fim de obter a prioridade nas políticas de Estado para esse setor. Essa mudança teria acontecido, em especial, após o início da Operação Lava-Jato que atingiu as grandes construtoras nacionais.

ABSTRACT. The political and economic crisis in Brazil was based on the reorganization of classes in the power block. This article has as object the construction industry in Brazil along the governments Dilma Rousseff (2011-2016). We use the concepts of bourgeois fraction and block in power developed by Nicos Poulantzas to explain important conflicts present in the Brazilian political process. Our hypothesis is that during the crisis of Dilma Rousseff's government there was a deepening of the public budget dispute among the bourgeois fraction, and this led to a change in the political position of the civil construction capital, which ceased to play a subordinate role to the great capital and began to act openly against him. In other words, the middle capital of civil construction constituted itself as an autonomous fraction of the capitalist class, in order to obtain priority in the state policies for this sector. This change would have occurred, in particular, after the start of Operation Lava-Jato that hit the big national constructors. 


\section{Indústria da construção civil e bloco no poder no Brasil}

Este artigo pretende analisar a indústria da construção civil brasileira no contexto dos governos Dilma Rousseff (2011-2016) com o objetivo de compreender os conflitos entre os diversos extratos dos capitais investidos nesse setor e a relação deles com o governo federal, em especial por se tratar de uma conjuntura de crise que culmina no processo de ruptura institucional em 2016. Também porque esse setor teve desempenho de destaque na política e na economia brasileira durante os governos petistas (2003-2016), uma vez que compunha o núcleo da hegemonia neodesenvolvimentista (BOITO JR., 2018) no Brasil.

Nesse sentido, é importante destacar que o nosso objeto de análise é relevante para a compreensão da crise porque não apenas as médias empresas da indústria da construção civil que atuam no Brasil são firmas de capital nacional, mas também ao menos onze das quinze maiores ${ }^{1}$. Assim, entendemos que esse setor é representativo $^{2}$ do que denominamos grande burguesia interna ${ }^{3}$. A importância da construção civil está no fato de que essa foi a fração de classe mais privilegiada pelas políticas dos governos petistas e ela manteve a sua posição hegemônica até a conjugação da crise do governo Dilma com a deflagração da Operação Lava Jato.

O conflito entre as frações burguesas no Brasil ao longo das últimas décadas se materializou em conflitos que colocaram de um lado os segmentos integrados ao capital internacional (burguesia associada) e, de outro, os segmentos que embora sejam dependentes do capital internacional, possuem conflitos moderados com ele (burguesia interna). Encontramos as raízes desse conflito em fatos anteriores ao que descreveremos, mas para o estabelecimento de um parâmetro da dinâmica desse conflito na política recente no Brasil, destaco que o avanço do neoliberalismo que ocorreu na década de 1990 foi consequência da hegemonia da grande burguesia associada no bloco no poder ${ }^{4}$. Isso significa que o Estado priorizou os interesses das

\footnotetext{
${ }^{1}$ As outras quatro, apesar de obrigadas por lei, não divulgam seus dados. São elas: Engesa SA., Carioca Engenharia, Schahin e a Construtora A.R.G (SABENÇA, 2014).

${ }^{2} \mathrm{~A}$ grande burguesia interna é distribuída por diversos setores além da construção civil, como a mineração, o agronegócio, a indústria de transformação e os grandes bancos privados e estatais de capital predominantemente nacional. (BOITO, 2018, p. 108).

3 A burguesia interna é, segundo Poulantzas (1977), a fração que assume uma posição intermediária entre a burguesia nacional e a burguesia associada. Ela é dependente do capital internacional, mas a sua acumulação de capital se da internamente à sua formação social, de modo que conflitos pontuais com o capital internacional surgem à medida que ele representa uma ameaça ao mercado interno.

4 Bloco no poder é a unidade contraditória das camadas, classes e frações das classes dominantes de um determinado modo de produção em uma formação social específica, a fim 
frações associadas diretamente ao grande capital internacional (BOITO JR., 1999), o que acabou lesando parte dos interesses da grande burguesia interna.

De tal modo, novos conflitos entre essas frações ocorreram, como aquele importante que se deu em torno da proposta de Área de Livre Comércio das Américas (ALCA), que despertou reação da grande burguesia interna à passividade da grande burguesia associada diante das ações do capital internacional (BERRINGER, 2015). Sentindo-se ameaçada, a grande burguesia interna se aproximou do movimento popular a fim de barrar os pontos programáticos mais danosos à indústria nacional. Essa aliança contraditória tomou forma de uma frente política e fez com que a grande burguesia interna lograsse a hegemonia no bloco no poder (BOITO JR., 2018) de maneira mais evidente a partir do segundo mandato de Lula (2007-2010).

Nos governos petistas, portanto, a indústria da construção civil tornou-se um dos setores mais importantes na política de Estado, inclusive pelo papel na política externa que passou a cumprir. Configurou-se a partir dessa cadeia econômica um dos maiores setores de exportação de serviços do Brasil. A Odebrecht, por exemplo, assumiu papel importante no cenário político e econômico internacional. A primeira obra realizada por ela no exterior foi uma hidroelétrica no Peru, em 1979. Hoje está em 25 países, além do Brasil, e tem apenas em Angola, gestão da metade dos 65 empreendimentos realizados desde 2006. A empresa chegou à África em 1984, após se aliar ao Movimento Popular de Libertação de Angola (MPLA) em meio à guerra civil no país e chegou a gerir 10\% dos 15 bilhões de dólares (CABRAL \& OLIVEIRA, 2017. Pp. 206) investidos por esse governo.

O rápido crescimento econômico da construção civil iniciado após a eleição de Lula da Silva e encerrado no governo de Dilma foi resultado da ascensão da grande burguesia interna à posição hegemônica dentro do bloco no poder ${ }^{5}$ brasileiro. Posição que essa fração de classe apenas logrou porque soube utilizar o seu papel de força dirigente da frente política neodesenvolvimentista (BOITO JR., 2018) contando com a força social de parcela da fração organizada da classe trabalhadora e com grande parte dos trabalhadores da massa marginal, que cumpriram papel de classe-apoio ${ }^{6}$.

do compartilhamento do poder político e da manutenção de seus objetivos políticos estratégicos em comum (POULANTZAS, 1977).

${ }^{5} \mathrm{~A}$ fração de classe hegemônica no bloco no poder tem a capacidade de fazer com que o Estado privilegie o seu programa econômico em detrimento do de outras frações de classe (SAES, 2001, Pp. 50).

${ }^{6}$ As classes ou frações de classe-apoio distinguem-se das classes ou frações do bloco no poder e das classes ou frações aliadas a ele. No primeiro caso a diferenciação se dá pelas contradições entre ambas e no segundo devido ao fato de que a sustentação que as classes ou frações-apoios dão ao bloco no poder "não é em geral baseado em qualquer sacrifício político real dos interesses do bloco no poder e das classes aliadas em seu favor" (POULANTZAS, 1977, Pp. 238). 
Desse modo, é preciso notar que uma frente política policlassista possui contradições, como as que existem entre o grande capital financeiro nacional e o grande capital industrial nacional, entre o agronegócio e a grande indústria nacional, entre o agronegócio e os movimentos sociais de camponeses, entre a grande indústria nacional e o movimento sindical (BOITO JR., 2018, p. 66). Com o decorrer das crises política e econômica e da Operação Lava Jato, percebemos que dentro de alguns setores econômicos que compõem a fração da grande burguesia interna houve conflitos que colocaram de um lado o médio capital e de outro o grande. Acreditamos que esse foi o caso da indústria da construção civil ${ }^{7}$.

\section{Os conflitos na indústria da construção civil}

Em 2003, quando Lula assumiu a presidência da república, o número de empresas registradas no setor da construção civil era de 118 mil, o número de trabalhadores ocupados era de 1,4 milhão e o gasto anual em pessoal era de quase 20 bilhões (IBGE, 2003) ao passo que no ano de 2016 esses números foram respectivamente de 127 mil, 2 milhões e 58,5 bilhões (IBGE, 2016). Como vimos, o avanço econômico do setor nos governos petistas é decorrente da prioridade que o Estado brasileiro deu a política econômica e social da grande burguesia interna que era a fração hegemônica. Tal prioridade pode ser averiguada nas medidas tomadas pelo Estado que a beneficiaram diretamente como, por exemplo, as grandes obras do Programa de Aceleração do Crescimento (PAC), o programa Minha casa Minha Vida (MCMV), as obras efetivadas devido à realização de grandes eventos como a Copa e as Olimpíadas, a transposição do Rio São Francisco e as grandes hidroelétricas.

Contudo, a forte ativação desse setor econômico não se espraiou sem gerar contradições, uma vez que grande parte do montante do financiamento estatal envolvido para que se desenrolassem todos esses projetos que envolviam a construção civil nos governos petistas privilegiou o grande capital em detrimento do médio. Agravando-se a situação houve, no mesmo período, o surgimento de cerca de 9 mil pequenas e médias empresas do ramo da construção, o que alimentou o descontentamento desses estratos com a política econômica petistas, já que ela aumentou a competição entre as pequenas e médias empresas, que já tinham que competir pela menor fatia do orçamento.

\footnotetext{
7 A cadeia produtiva da construção civil é composta pelos seguintes segmentos: Construção $(66,2 \%)$ Indústria de materiais $(11,8 \%)$, Comércio de materiais $(8,6 \%)$, Serviços $(5,1 \%)$ e Máquinas, equipamentos $(0,7 \%)$ e outros fornecedores (7,7\%). (CBIC, 2016b).
} 
A fala do consultor Aldo Mattos ${ }^{8}$ no programa Jogo do Poder exemplifica o caso. Segundo ele, existem três principais problemas para as médias empresas no processo licitatório. O primeiro é que devido ao cartel existente entre as poucas grandes empresas, o médio capital não tem experiência em obras públicas de grande porte e não conseguem, por isso, a documentação junto ao Conselho Regional de Engenharia Arquitetura e Agronomia (CREA) para concorrer às licitações. O segundo é que o contratante público não paga em dia e com os atrasos as grandes obras ficam inviáveis para as médias empresas porque elas não têm o capital de giro suficiente em caixa corrente para cobrir os atrasos e garantir a manutenção das obras. Por fim, Mattos se refere à Lei $8.666 / 93^{9}$ que, segundo ele, impede a melhora da eficiência das obras públicas (MATTOS, 2017).

Na mesma entrevista, o descontentamento com a prioridade do Estado para com o grande capital interno ${ }^{10}$ ficou explicito quando, falando sobre a Operação Lava Jato, Aldo diz que o combate à corrupção no Brasil será um divisor de águas, sobretudo para as grandes construtoras, pois, na verdade, a intenção é desmontar o cartel das grandes obras estruturantes do país. Ainda sugere que no futuro próximo as grandes empresas que estão em processo de recuperação judicial "para se salvar vão ter que vender ativos, vão ter que mudar de marca, vão ter que mudar de nome e vão ter que mudar também seus quadros" (MATTOS, 2017).

O descontentamento das médias empresas também foi explicitado pela Associação das Pequenas e Médias Empresas da Construção Civil do Estado de São Paulo (APEMEC). A Associação assume a defesa das investigações contra a corrupção (APEMEC, 2015) que atingem as grandes empresas do setor, elogia a nova regulamentação que permite a responsabilização de pessoa jurídica e o fato de a inspiração de tais leis serem a Organização para a Cooperação e Desenvolvimento Econômico (OCDE) e antecipa, por isso, o sucesso da Lei Anticorrupção (BRASIL, 2015) no Brasil.

A APEMEC ainda sustenta as criticas da OCDE à política de compliance internacional das empresas brasileiras e afirmam que competirá aos agentes envolvidos nesse combate "acolher as sugestões da própria OCDE para o Brasil,

\footnotetext{
8 Aldo Mattos é engenheiro, advogado e consultor de empresas como Andrade Gutierrez, Odebrecht e OAS. Em nosso entendimento, Mattos não representa o médio capital da construção civil, mas seus apontamentos podem estar corretos sobre a ação política desse estrato. Como representante oficial dos diversos estratos da indústria da construção civil, utilizaremos os documentos das respectivas associações.

9 Trata-se da Lei que normatiza os processos de licitações e contratos de obras e serviços de todos os níveis de poderes. (BRASIL, 1993).

10 A construção civil tem proteção desde 1969, quando foi decretada a lei 64.345 , que determina que as obras públicas sejam realizadas por empresas brasileiras (CABRAL, OLIVEIRA, 2017).
} 
sempre adaptando à realidade pátria" (APEMEC, 2015). A Associação, no entanto, é cuidadosa e separa o médio capital das operações contra a corrupção praticada pelo grande capital. Segundo a APEMEC, ficou constatado que o corruptor e o envolvimento de pessoas jurídicas são capitais de "grande porte, com a participação ativa de diretores e executivos, que utilizaram intermediários para realização de pagamentos aos agentes públicos com o intuito de burlar o processo de contratação" (APEMEC, 2015). Parte desse anseio virou expectativa de que com o decorrer das investigações da Operação Lava Jato, o médio capital passaria a assumir parcela do mercado do grande capital (MATTOS, 2016).

No site da Câmara da Indústria da Construção Civil (CBIC) também encontramos o mesmo teor citado acima como, por exemplo, a matéria intitulada Escândalo de corrupção abre espaço ao pequeno construtor (CBIC, 2015). Nela, afirma-se que o "interesse do governo sempre foi fazer negócio com grandes grupos, pelo alto volume de caixa, mas esse cenário deve mudar com a redução do apetite delas por concessões públicas" (CBIC, 2015) já que a previsão é de que "os escândalos de corrupção diminuam o apetite das gigantes por concorrências públicas e abram espaço para consórcios de pequenas e médias" (CBIC, 2015). Acrescenta ainda que para "competir com uma grande construtora, é preciso ter o caixa e o nome que ela tem, e isso só se consegue juntando entre 12 e 15 empresas menores" (CBIC, 2015), o que demonstra a ciência da importância do processo de organização e articulação política para disputarem o mercado nacional de obras públicas com as grandes empresas do setor.

A contradição se explicita quando notamos que esse ramo econômico teve 600 empresas fechadas e perdeu 120 bilhões de reais em receitas em dois anos (SINDUSCOM-SP, 2018). A queda em 2016 foi de 14,8\% em relação a 2015, quando já havia ocorrido uma queda de 15,9\% segundo os resultados da Pesquisa Anual da Indústria da Construção (PAIC) (IBGE, 2016). Esses dados nos trazem outras duas informações importantes. A primeira é que o alto número de empresas fechadas corresponde a empresas de pequeno e médio porte, já que temos poucas empresas consideradas grandes (SABENÇA, 2014) e nenhuma delas fechou, apesar de terem sido reduzidas em seu poder econômico e político. Os cálculos do economista João Sicsú (2017) mostram que a empreiteira OAS reduziu de 120 mil para 30 mil trabalhadores contratados no ano de 2017 e a Engevix de 20 mil para 3 mil. A hipótese levantada por nós sobre a divisão entre o médio capital de um lado e de outro o grande tem, portanto, antes das consequências políticas, lastro material.

Diante da constatação de que há grande descontentamento do pequeno e do médio capital da construção civil em relação ao grande e sua posição vantajosa 
perante as políticas de Estado dos governos do PT, abre-se, para nós, a hipótese de que o enfraquecimento político do grande capital da construção civil pode ter sido um fato significativo para a derrota da frente neodesenvolvimentista na crise política de 2015 que culminou com o impeachment, e a consequente ruptura institucional, de Dilma Rousseff em 2016.

\section{O combate à corrupção no Brasil e o bloco no poder neodesenvolvimentista}

A conjugação das crises política e econômica com a atuação da burocracia de Estado através da Operação Lava Jato teve forte impacto na conjuntura nacional, em especial a da construção civil ${ }^{11}$ e causará mudança estrutural nessa cadeia produtiva.

Parte significativa desse impacto sofrido, sobretudo pelo grande capital, deve-se às operações contra a corrupção que atingiram a construção civil, uma vez que elas paralisaram diversas grandes obras públicas. Algumas consultorias "divulgaram estudos que avaliam que do resultado negativo do PIB de $3,8 \%$ em 2015 e de $3,6 \%$ em 2016, estima-se que a operação é responsável por entre 2 e 2,5 pontos percentuais da queda de cada ano. Em outras palavras, se não fosse a Lava Jato, a recessão de cada ano teria sido algo em torno de 1,5\%" (SíCSU, 2017). Desse modo, para entender o setor econômico da construção civil no contexto dos governos petistas e o seu lugar na ruptura institucional temos que analisar além das crises política e econômica, a variável Operação Lava Jato ${ }^{12}$.

São duas as frentes de análise para compreender a Lava Jato. A primeira é a dimensão interna, que diz respeito ao fato de que no período dos governos petistas ocorreram mudanças qualitativas e quantitativas no burocratismo ${ }^{13}$ de Estado brasileiro, em especial no ramo do judiciário. A segunda é a dimensão externa, já que constatamos uma influencia de organismos internacionais na remodelagem do padrão de atuação do judiciário e da política de compliance das grandes construtoras brasileiras.

\footnotetext{
11 Um dos reflexos dessa conjugação no setor da construção civil é demostrado através da diminuição considerável da participação das obras de infraestrutura na porcentagem total das atividades que caiu de 41,3\% em 2007 para 29,5\% em 2016 (SINDUSCONSP, 2018b).

12 Sobre a Lava Jato, vale ressaltar que, essa operação afetou centralmente os dois principais setores da economia brasileira: a construção civil, que fazia investimento próximo na casa dos $2,8 \%$ do PIB, e a petroquímica, que tinha $2 \%$ de investimento do PIB só através da Petrobrás. São os principais ramos, portanto, por terem sido os pilares do crescimento econômico nos anos 2000, com as políticas econômicas e sociais da grande burguesia interna na posição hegemônica no bloco no poder. (SICSÚ, 2017)

13 Burocratismo é "um modo particular de organização e de funcionamento do aparelho de Estado coextensivo, no caso do Estado capitalista, à categoria burocrática específica. $O$ burocratismo é, nesse caso, tanto as estruturas do Estado capitalista como ao impacto da ideologia capitalista dominante sobre as regras normativas de organização do aparelho de Estado" (POULANTZAS, 1977, p. 343).
} 
Atentando-nos inicialmente à dimensão interna, notamos que em 2003 a Controladoria Geral da União (CGU) contava com 1.430 integrantes de carreira, e no final de 2009 contava com 2.286 (HEGE, 2010). O salário inicial de analista passou de 3.659,54 para 12.960, 77 entre 2003 e 2009. Em seus estudos, Frederico de Almeida (2016) nos mostra que também houve mudanças de ordem institucional e ideológica. Se tomarmos como exemplo o Ministério Público (MP), veremos que desde a constituição de 1988 ele sofre reformulações institucionais que Ihe dão autonomia funcional em relação ao poder executivo. Mas esse processo não é resultado exclusivo de mudanças legais e constitucionais, também sofre impacto da elaboração e desenvolvimento de uma ideologia institucional de defesa do interesse público e de uma aproximação entre o judiciário e a sociedade civil (ALMEIDA, 2016).

O fato é que "a autonomização e a profissionalização das instituições e carreiras jurídicas não significa necessariamente um afastamento das instituições de justiça em relação ao mundo da política ou sua despolitização" (ALMEIDA, 2016, p. 72). Ao contrário, o autor mostra que apesar do distanciamento das instituições judiciais da política ser um fato, "a profissionalização das carreiras e a autonomia institucional deu aos juristas novos recursos de intervenção política" (idem). Fica evidente, portanto, que a mudança qualitativa do judiciário permitiu novos recursos jurídicos.

Quando Mattos demonstra preocupação sobre a entrada de empreiteiras estrangeiras no Brasil para suprir a possível ausência de grandes empresas da construção no período pós Lava Jato, ele evidencia uma questão externa a ser analisada. O consultor afirmou temer, sobretudo, as empresas chinesas porque elas trabalham com tecnologias e operários próprios. No entanto, parece relativizar a entrada de outros capitais, já que afirma que o capital europeu, por exemplo, está se associando às médias empresas brasileiras para barganharem parcela do mercado brasileiro e conhecimento da burocracia das licitações nacionais (MATTOS, 2017). O consultor não previu, contudo, o que vem ocorrendo nos primeiros meses de 2019 no governo Bolsonaro, que é o retorno das grandes empreiteiras norte-americanas (ALVES, 2019), como a Halliburton.

O grande capital da construção civil não sofreu, portanto, exclusivamente pressão política do médio capital e da burocracia de Estado, também sofreu pressão do capital internacional. Peter Bratsis (2017) tem mostrado em suas pesquisas, que organismos internacionais vinculados direta ou indiretamente ao capital financeiro internacional se utilizam da luta contra a corrupção nos países subdesenvolvidos para minimizar a influência política e econômica das burguesias internas locais sobre o seu Estado e a sua economia. Ou seja, o combate internacional à corrupção tem servido para que o capital internacional logre melhores posições na economia dos países 
subdesenvolvidos. No caso brasileiro, a indústria da construção civil foi fortemente atingida por ele.

A pressão política do Banco Mundial ${ }^{14}$ e do Fundo Monetário Internacional (FMI, 2017) se fazem presentes no Brasil. O relatório do FMI faz, por exemplo, uma série de recomendações, incluindo "produzir estatísticas fiscais abrangentes sobre o setor público, além de incorporar todas as empresas públicas nos dados sobre empresas públicas não financeiras e dar mais informação abrangente sobre todo o setor público" (NAÇÕES UNIDAS, 2017). Sugere ainda, mais "transparência sobre a relação entre bancos públicos e outras partes do setor público, além de fortalecer a divulgação de informações de transações entre o Banco Central do Brasil e o Tesouro Nacional" (NAÇÕES UNIDAS, 2017). Em síntese, querem que o Brasil abra os dados econômicos de setores estratégicos da sua economia, como os bancos públicos (que são os financiadores da grande burguesia interna) e as empresas estatais (que são alvos das políticas de privatizações). Ainda afirmam, que a luta por tal transparência só será próspera se for capaz de mobilizar a sociedade e a universidade.

Essa pressão política não foi apenas nos governos Dilma. Diante dela, Lula passou a seguir os padrões de conduta institucional e aumentou o poder da burocracia, como já constatamos com Frederico Almeida (2016). Jorge Hage (2010), ministro da Controladoria Geral da União (CGU) de 2006 a 2014, mostrou a influência do direito norte-americano no trabalho do judiciário brasileiro. A opinião do autor é de que nós poderíamos "mudar nossa legislação penal e processual e, junto com ela, mudar a interpretação que vem sendo dada a certos princípios constitucionais, sobretudo os famosos "ampla defesa" e "presunção de inocência"” (HAGE, 2010, Pp. 17/18), dando moldes semelhantes às dos EUA que "tem uma rápida e pesada condenação" para crimes financeiros.

O fato é que as concessões realizadas nos governos Lula geraram reconhecimento do capital internacional, que colocou o Brasil em posição exemplar para organismos como a OCDE, a OEA e o órgão especializado das Nações Unidas, a UNODC, quando o tema é o combate à corrupção. O professor Stuart Gilman, consultor do Banco Mundial e da ONU, foi ainda mais específico afirmando que a CGU brasileira é um centro de referência para outros países (HAGE, 2010).

\footnotetext{
${ }_{14}$ O Banco Mundial tem defendido publicamente a realização de intervenções globais contra a corrupção (BANCO MUNDIAL, 2014). Em processo paralelo, o banco tem recrutado ativistas sociais contra a corrupção em todo o mundo, como o exemplo da brasileira Nicole, que é ativista desde 2003 e foi selecionada para o Fórum Global Conta a Corrupção (BANCO MUNDIAL, 2012). O ano do recrutamento também chama atenção porque é o primeiro ano do governo neodesenvolvimentista. Dois anos depois, em 2005, surgiu a primeira denuncia de corrupção, conhecida como mensalão.
} 
A hipótese que esse artigo levanta é, portanto, a de que a pressão política realizada por esses organismos internacionais - nos quais o capital financeiro internacional tem pesada influência (BRATSIS, 2017) - para o combate à corrupção teve, no Brasil, reflexos na indústria da construção civil, já que dentro da fração da grande burguesia interna ela foi um dos setores mais atingidos com essa ofensiva do capital internacional durante a crise econômica e política no Brasil. O documento Integridade no Setor de Construção elaborado pela Pacto Global (ONU, 2018) junto com as grandes construtoras brasileiras ${ }^{15}$ envolvidas em investigações contra corrupção, indica ser uma manifestação concreta da vitória do capital financeiro internacional, pois o documento assume o padrão proposto ${ }^{16}$ pela instituição que está sob influência hegemônica daquele capital.

Em síntese, a indústria da construção civil faz parte da burguesia interna e compôs a frente neodesenvolvimentista que sustentou os governos petistas de Lula da Silva e Dilma Rousseff (BOITO JR., 2018). Com o agravamento da crise política e econômica no segundo governo Dilma e a ofensiva internacional, formou-se uma conjuntura propícia à divisão da ação política do setor da construção civil, ficando de um lado o pequeno e o médio capital e de outro o grande.

No entanto, esse conflito não é novo. A burguesia interna (todos os estratos dela) tem a característica de movimentar-se politicamente em busca de seus interesses econômicos imediatos (GORENDER, 1985), ou seja, através da política de curto prazo. Em períodos de crise esse fato se explicita com mais contundência na política concreta, uma vez que aumenta a disputa pelo orçamento da União. Como nos governos petistas a posição hegemônica foi ocupada pela grande burguesia interna e a posição secundária foi compartilhada pela grande burguesia associada e pelo grande capital financeiro internacional (BOITO JR., 2018), a média burguesia interna ocupou uma posição subordinada à grande burguesia interna.

O que ocorre é que, devido ao grande investimento em programas sociais como o MCMV, esses conflitos aumentaram de intensidade e importância porque o grande capital da construção civil também passou a ocupar uma posição antes ocupada pelo médio capital desse setor (CABRAL \& OLIVEIRA. 2017. p. 219). Além disso, é possível notar que a parceria entre esses organismos internacionais e as instituições brasileiras é eficaz na pressão política e econômica que fazem. Como fica evidente na reportagem da Câmara da Indústria da Construção, onde lemos que as empresas estão atentas às observações internacionais e as recomendações feitas, "estão cada

\footnotetext{
${ }^{15}$ Andrade Gutierrez, Camargo Corrêa Infra, Queiroz Galvão e Odebrecht.

${ }^{16}$ As propostas também ocorrem através de workshops, como "Como coibir ações corruptas" e "Boas práticas e aprendizados em ações coletivas de combate à corrupção".
} 
vez mais interessadas em criar ou aparelhar seus departamentos de ética e compliance para que seja preservada a sua imagem no ambiente competitivo do mercado" (CBIC, 2016). Ou seja, as empresas também são acuadas e adotam o padrão de compliance internacionais pela via da pressão econômica.

\section{Em vias de uma conclusão}

Nesse sentido, levantamos a hipótese de que diante da pressão que atingia em especial as grandes construtoras, o médio capital desse setor - que não tem grande expressão na cena política a não ser em questões pontuais e de forma limitada, como mostrou Mancuso (2003) - apostou que, com a deflagração da Operação Lava Jato e com a ofensiva neoliberal contra a grande burguesia interna em uma conjuntura de crise econômica, eles teriam uma oportunidade para avançar sobre uma parcela do mercado de obras públicas se associando ao grande capital internacional. Desse modo, o médio capital se aliou ao capital financeiro internacional e agiram contra o grande capital interno da construção civil e impuseram uma derrota a ele expressa no documento Integridade no Setor de Construção, que foi lançado no ano de 2018.

O médio capital também parecia ter saído vitorioso na mudança sofrida na direção da Associação Brasileira da Infraestrutura e Indústrias de Base (ABDIB), que ocorreu logo após a queda de Dilma Rousseff. O presidente da associação, Paulo Godoy, foi substituído por Venilton Tadini, neoliberal e privatista, mas que estava encaminhando as demandas do médio capital ao governo a fim de obter o acesso às licitações públicas para essas construtoras. Saiu uma direção mais ligada à grande burguesia interna e, ao que tudo indica, a nova direção é mais ligada ao médio capital interno e ao capital internacional. O sindicato patronal também estava vocalizando o programa do médio capital, como ficou claro em seu posicionamento sobre a atualização da Lei de Licitações. O documento denuncia que os novos percentuais provavelmente impedirão as pequenas e médias empreiteiras de participarem de novas licitações e novos contratos, pois “vão 'estourar' os limites de contratação de seguros destas empresas junto às seguradoras. Mais uma vez corre-se o risco de restringir o número de participantes das licitações, abrindo a porta a conluios" (SINDISCOM-SP, 2018c).

O próprio governo interino de Michel Temer (2016-2018) explorou essa nova configuração dos conflitos políticos em um discurso no lançamento de nova linha de crédito pelo BNDES no valor de 20 bilhões de reais para micro, pequenas e médias empresas. Na cerimônia de lançamento da nova linha de crédito, o presidente do 
BNDES, Paulo Rabello de Castro, afirmou que a meta é "ampliar a participação das pequenas empresas na carteira do banco ao longo do governo Temer" (MAZUI, 2017).

Em síntese, nossa pesquisa aponta que na conjuntura de crise política e econômica do governo Dilma o setor da construção civil se fragilizou com a divisão da posição política dos seus diversos estratos. Somando-se a isso, o fato de que a Operação Lava Jato atingiu prioritariamente esse setor, que era o núcleo da hegemonia no bloco no poder nos governos petistas, criou-se uma conjuntura em que era inevitável a ruptura institucional que se ameaçava devido à falta de sustentação política, inclusive entre o grande empresariado. As medidas tomadas no governo de Temer pareciam indicar que a intenção era construir uma nova configuração para o bloco no poder em que o médio capital passasse a se subordinar (ou se associar) ao capital internacional, e não mais ao grande capital interno. O que vemos no governo Bolsonaro é que essa tendência se confirma. O capital internacional está ocupando o lugar da grande burguesia interna na cadeia da construção civil pesada e não o médio capital.

\section{REFERÊNCIAS}

ALMEIDA, Frederico de. Justiça, combate a corrupção e política. Uma análise a partir da Operação Lava Jato. Revista Pensata. V.5, N.2. Nov. 2016.

ALVES, Gonzaga. A Lava Jato destruiu as construtoras brasileiras para entregar obras do país às empreiteiras dos EUA. 02/08/2019. Jornal GGN. Disponível em: https://jornalggn.com.br/crise/a-lava-jato-destruiu-as-construtoras-brasileiras-para-

entregar-obras-do-pais-as-empreiteiras-dos-eua-por-gonzaga-alves/. Acessado em: 30 de ago. de 2019.

APEMEC. As leis brasileiras e a corrupção internacional. 16/03/2015. Disponível em: http://www.apemec.com.br/noticias-materia/03/16/2015/as-leis-brasileiras-e-acorrupcao-internacional/index.php. Acesso em: 24 de ago. de 2019.

BANCO MUNDIAL. O relatório sobre integridade do Grupo Banco Mundial defende intervenções globais sustentadas para ultrapassar os desafios transnacionais da corrupção. 08/10/2014. Disponível em: https://www.worldbank.org/pt/news/press-release/2014/10/08/world-bank-groupintegrity-report-sustained-global-interventions-transnational-corruption-challenges. Acessado em: 26 de ago. 2019.

brasileiros. 09/11/2012. Disponível em: https://www.worldbank.org/pt/news/feature/2012/11/09/Brazil-youth-social-media-fightcorruption. Acessado em: 26 de ago. 2019.

BERRINGER, Tatiana. A burguesia brasileira e a política externa nos governos FHC e Lula. Curitiba, Appris, 2015] BOITO Jr., Armando. Reforma e crise política no Brasil. Os conflitos de classe nos governos do PT. Campinas, Editora Unicamp, 2018.

BRASIL. Lei $n^{\circ}$ 8.666, de 21 de junho de 1993. Regulamenta o art. 37, inciso XXI, da Constituição Federal, institui normas para licitações e contratos da Administração Pública e dá outras providências. Disponível em: 
http://www.planalto.gov.br/ccivil 03/Leis//8666cons.htm. Acessado em: 26 de ago. de 2019.

Lei $\mathrm{n}^{\circ}$ 12. 846, de 1 de agosto de 2013. Dispõe sobre a responsabilização administrativa e civil de pessoas jurídicas pela prática de atos contra a administração pública, nacional ou estrangeira, e dá outras providências. Disponível em: http://www.planalto.gov.br/ccivil 03/ ato20112014/2013/lei/l12846.htm. Acessado em: 26 de ago. de 2019.

BRATSIS, Peter. A corrupção política na era do capitalismo transnacional. Revista Crítica Marxista, N 44, Pp.21 - 42.

CABRAL, Marcelo \& OLIVEIRA, Regiane. O Príncipe. Uma biografia não autorizada de Marcelo Odebrecht. São Paulo, Astral Cultural, 2017.

CBIC. Escândalo de corrupção abre espaço ao pequeno construtor. 10/03/2015. Disponível em: https://cbic.org.br/escandalo-de-corrupcao-abre-espaco-ao-pequenoconstrutor/. Acessado em: 24 de ago. 2019.

CBIC apoia tendência mundial de combate à corrupção e apresenta propostas para coibir desvios. 04/11/2016a. Disponível em: https://cbic.org.br/cbicapoia-tendencia-mundial-de-combate-a-corrupcao-e-apresenta-propostas-para-coibirdesvios-2/. Acessado em: 24 de ago. 2019.

Composição da cadeia produtiva da construção por participação (\%) no PIB total da cadeira - 2016. 2016b. Disponível em: http://www.cbicdados.com.br/media/home/Cadeia produtiva 2016 participação.jpg. Acessado em: 26 de ago. 2019.

FARIAS, Francisco Pereira de. Frações burguesas e bloco no poder: uma reflexão a partir do trabalho de Nicos Poulantzas. In: Crítica Marxista, n. 28, p. 81-98, nov./2009.

FMI. Brazil: Fiscal Transparency Evaluation. 03/05/2017. Disponível em: https://www.imf.org/en/publications/cr/issues/2017/05/03/brazil-fiscal-transparency-

evaluation-44874. Acessado em: 26 de ago. 2019.

GORENDER, Jacob. A burguesia brasileira. Editora Brasiliense, 1985.

HAGE, Jorge. O governo Lula e o combate à corrupção. São Paulo, Editora Fundação Perseu Abramo, 2010.

IBGE. Pesquisa Anual da Indústria da Construção 2003. Rio de Janeiro, v.13, p. 175, 2003.2 Disponível em: https://biblioteca.ibge.gov.br/visualizacao/periodicos/54/paic 2003 v13.pdf. Acessado em: 26 de ago. de 2019.

Pesquisa Anual da Indústria da Construção 2016. Rio de Janeiro, v. 26, p. 14, 2016.2 Disponível em: https://biblioteca.ibge.gov.br/visualizacao/periodicos/54/paic 2016 v26 informativo.pdf . Acessado em: 24 de ago. de 2019.

MANCUSO, Wagner. Construindo leis: as construtoras e as concessões de serviços. Revista Lua Nova, N 58, 2003.

MATTOS, Aldo Dórea. Jogo do Poder Notícias. [jul. 2017]. Entrevistador Zilan Costa e Silva. $28 \mathrm{~min}$. Entrevista concedida ao Jogo do Poder Notícias. Disponível em: https://www.aldomattos.com/jogo-do-poder-noticias-com-zilan-costa-e-silva/. Acessado em: 26 de ago. de 2019.

Perspectivas para o setor de construção civil em 2017. Construct, 21/12/2016. Disponível em: https://constructapp.io/pt/perspectivas-para-osetor-de-construcao-civil-em-2017/. Acesso em: 24 de ago. de 2019.

MAZUI, Guilherme. Em evento no Planalto, BNDES lança crédito de $\mathbf{R} \mathbf{\$} 20$ bilhões para micro e pequena empresas. Cerimônia teve participação do presidente Michel Temer. Programa BNDES Giro prevê disponibilizar os novos financiamentos até agosto de 2018. 23/08/2017. Disponível em: https://g1.globo.com/economia/noticia/em-evento-no-planalto-bndes-lanca-credito-de-r20-bilhoes-para-micro-e-pequena-empresas.ghtml . Acessado em: 24 de ago. de 2019. 
NAÇÕES UNIDAS, FMI faz uma série de recomendações para Brasil ampliar sua transparência fiscal. 31/05/2017. Disponível em: https://nacoesunidas.org/fmi-fazuma-serie-de-recomendacoes-para-brasil-ampliar-sua-transparencia-fiscal/. Acessado em: 24 de ago. 2019.

Pacto Global debate papel de empresas, governos, ONGs e Universidades no combate à corrupção. 17/05/2018. Disponível em: https://nacoesunidas.org/pacto-global-debate-papel-de-empresas-governos-ongs-euniversidades-no-combate-a-corrupcao/. Acessado em: 24 de ago. de 2019.

POULANTZAS, Nicos. Poder Político e Classes Sociais. São Paulo: Martins Fontes, 1977.

SABENÇA, Mariana. As grandes construtoras e a política econômica dos governos Lula e Dilma. Caxambu, ANPOCS, 2014. Disponível em: https://anpocs.com/index.php/papers-38-encontro/gt-1/gt13-1/8960-as-grandes-

construtoras-e-a-politica-economica-nos-governos-lula-e-dilma/file. Acessado em: 24 de ago. 2019.

SíCSU, João. Quantos empregos custa a Lava Jato?. Carta Capital, 27 de março de 2017. Disponível em: https://www.cartacapital.com.br/economia/quantos-empregoscusta-a-lava-jato. Acessado em: 24 de ago. 2019.

SINDUSCOM-SP. Indústria da construção fechou 600 empresas e perdeu mais de $\mathbf{R} \$ 120$ bilhões em receitas nos últimos dois anos. Participação das obras de infraestrutura teve forte queda entre 2007 e 2016, passando de $41 \%, 3 \%$ para $29,5 \%$ do valor adicionado. 08/12/2018a. Disponível em: https://sindusconsp.com.br/industria-da-construcao-fechou-600-empresas-e-perdeumais-de-r-120-bilhoes-em-receitas-nos-ultimos-dois-anos/. Acessado em: 24 de ago. de 2019.

- Participação das atividades da construção no total do valor adicionado. 2018b Disponível em: https://www.sindusconsp.com.br/wpcontent/uploads/2018/06/Paic_info2-08.06.2018.jpg. Acessado em: 24 de ago. de 2019.

Licitações sob risco. Projeto de Lei elevou excessivamente os valores máximos dos seguros de garantia de execução dos serviços exigíveis aos licitantes. 16/04/2018c. Disponível em: https://sindusconsp.com.br/opiniaolicitacoes-sob-risco/. Acessado em 24 de ago. de 2019. 